\title{
Co-Mordibity Pulmonary Arterial Hypertension/HIV in the Provinces' Cardiology
}

\author{
AbdoulayeKissima Traore, ZoumanaSangare, Modibo Doumbia*, Charles DARA, Boubacar \\ Diallo, AdamaSawadogo, Elie Dioma, Madou Traore, Ahmadou I Drame, Safi Bazi \\ Department cardiology ofSikasso, Mali, University of Bamako, Faculty de médicineet stomatology, Senegal \\ *Corresponding Author: Modibo Doumbia, Department cardiology of Sikasso, Mali, University of \\ Bamako, Faculty de médicineet stomatology, Senegal, Email:modibodoumbia25@yahoo.fr
}

\begin{abstract}
Introduction: The pulmonary arterial hypertension (PAT) gathers different affections that affect pulmonary arteries of minor diameter which progressively increase the resistance of pulmonary arteries and lead to a right heart failure. This complication is rare, but it is potentially lethal when associated with the human immunodeficiency virus (HIV).The purpose was to study the PAT for people living with HIV.
\end{abstract}

Population and Method: We have conducted a transverse descriptive survey within a 1-year period in people with PAT associated with an infection of HIV.

Results: In the survey, 12 patients have composed the sample divided up among 7 women and 5 men predominated by female patient. Age groups of 26-35 years old and 46-55 years old were the most involved with a frequency of $25 \%$. The signs of right heart failure were mainly found for (5) patients. The rate of lymphocyte CD4 were less than 200/ $\mathrm{mm}^{3}$ for (4) patients. The half of the patients (6) have had an increase of the size of the pulmonary artery visible on the chest $x$-ray. The left ventricular hypertrophy was visible on the electrocardiogram of (6) patients. On the trans-thoracic echocardiography, (8) patients have had a dilation of the right ventricle and (6) patients have had a serious PAT among them (5) have had a rate of lymphocyte CD4 higher than 200/ $\mathrm{mm}^{3}$. All the patients $(n=12)$ have undergone a triple antiretroviral therapy. The 6 deceased patients have undergone a triple antiretroviral therapy alone. On the other hand, we haven't record any death among patients which have undergone a triple antiretroviral therapy associated with a medical treatment of PAT.

Conclusion: The PAT is a major public health concern with a high morbidity-mortality. The prognosis depends on the precocity of its clinical care. The foremost consideration must be prevention, the early detection and the proper medical care of HIV infection.

Keywords: HIV-PAT- Triple Antiretroviral Therapy-Sikasso.

\section{INTRODUCTION}

The pulmonary arterial hypertension (PAT) is a serious affection due to the gradual increase of the resistance of pulmonary arteries that can be complicated to a right heart failure and led to death [1]. The infection by the human immunodeficiency virus (HIV) is known as a risk factor for PAT and represents $7 \%$ of cause of PAT diagnosed in France [2]. SubSaharan Africa is the area which has been heavily affected by the HIV epidemic worldwide, accounting for over two thirds (67\%) of all people living with HIV and for nearly three quarters $(72 \%)$ of AIDS-related deaths in 2008[3]. In Mali in 2006, the number of seropositive was estimated at $1,3 \%$ of a total of
$143000,0,6 \%$ of which was in Sikasso approximately 2,9 million of lives have been saved due to the access of anti-retroviral therapy. In Mali, free antiretroviral drugs were introduced by IMAARV in 2004 which has substantially improved patients' compliance and thus their survival [4]. This survey, the first of its kind in Mali and precisely in Sikasso intends as purpose to study the PAT for people living with HIV.

\section{Population ANd Method}

It was a transverse and descriptive study in the heart disease department of hospital of Sikasso over a year from 14th October 2012 to 14th October 2013 for patient admitted with PAT 
associated with an infection of HIV. The PAT has been diagnosed by the trans-thoracic echography through systolic pulmonary artery pressure with Tricuspid insufficiency or pulmonary insufficiency with a normal value lower than $30 \mathrm{mmHg}$. The different stages of the disease (slight, moderate, serious) were appreciated in accordance with age.

The studied parameters have concerned epidemiologic data and clinical record. The economic profile was evaluated according to the occupation, the number of person who has been taken care of, the monthly income of the person who has taken care of the patient and the equipment. All the collected parameters have been recorded and the instituted treatment has been noted. The patients have been seeing in order to knowing their development. The input mask, the capture data and analysis have been carried out with software like Word 2007 and SPSS 10.0 French version for Window.

\section{Results}

In the survey, 12 patients have composed the sample shared out into 7 women and 5 men with a gender balance of 1,4 in favor for women. The groups of age 26-35 years old and 46-55 years old were the most involved with a frequency of $25 \%$. The signs of right heart failure were mainly found in (5) patients. (4) patients have had a rate of lymphocyte CD4 less than $200 / \mathrm{mm}^{3}$. The half of the patients (6) have had an increase of the size of the pulmonary artery visible on the chest $\mathrm{x}$-ray. The left ventricular hypertrophy was visible on the electrocardiogram of (6) patients. On the trans-thoracic echocardiography, (8) patients have had a dilation of the right ventricle and (6) patients have had a serious PAT among them (5) have had a rate of lymphocyte CD4 higher than $200 / \mathrm{mm} 3$. All the patients $(n=12)$ have undergone a triple antiretroviral therapy. The 6 deceased patients have undergone a triple antiretroviral therapy alone. On the other hand, we haven't record any death among patients which have undergone a triple antiretroviral therapy associated with a medical treatment of PAT.

\section{DISCUSSION}

The PAT seems to be rare during the infection of HIV, but it is still a major factor to watch over. The limitation of the study was the lack of cardiac catheterization in the heart disease department. Contrary to our survey, Guillaume $M$ [2] in Grenoble has found a ratio in favor of men $(1,4)$. This difference could be explained by the small size of our sample. The groups of age 26-35 years old and 46-55 years old were the most involved with a frequency of $25 \%$. This lengthening of patients' age could be explained by the improvement in the better care of people living with HIV and thus their survival. The signs of right heart failure were mainly found in $50 \%$ which has made known that the presence of the right heart failure during the diagnosis of the PAT. Fifty percent of patients have had dilatation of pulmonary arteries which have witnessed a screening in our patients in late-stage disease. All the patients have undergone triple antiretroviral therapy. This result supports the data found in the literature [7, 8]. The half $(n=6)$ have had a serious PAT. It could be an obvious connection with an inadequate control of the infection of HIV or the weaker socioeconomic situation of our patients who decide to go into hospital only when some clinical signs appear. The (6) deceased patients have undergone a triple antiretroviral therapy alone. This result is comparable to the cases of Guillaume $\mathrm{M}$ and Opravil $\mathrm{M}$ and al $[2,9]$. On the other hand, we haven't record any death among patients which have undergone a triple antiretroviral therapy associated with a medical treatment of PAT. That is attested the effectiveness of those molecules on the PAT in accordance with Guillaume M [2].

\section{CONCLUSiON}

The PAT is a particular disease which poses a huge problem of screening, follow-up and treatment for our people on low incomes. Due to the lack of modern methods of therapy and challenges inherent in taking care of this affection, a particular emphasis should be placed on prevention, early screening of the scourge which represents HIV infection.

\section{REFERENCES}

[1] Savale L, Lador F, Jais X, Montani D, Simonneau G, Humbert M et al.

[2] Pulmonary hypertension associated with HIV. Rev resp diseases .2012, 29 (4): 491-500.

[3] Guillaume. M. HIV-associated pulmonary hypertension: survival and prognostic factors present these med. Grenoble 2009, 8p.

[4] Toure A M. changes in the level of adherence to antiretroviral therapy in children from 0 to 15 years of ONG WALE Ségou: these med. Bamako 2010, 15p.

[5] Diallo B A. Hypertension artérielleassociée au traitementantirétroviral. Thèseméd. Bamako: 2011, 12p. 
[6] Basse C. Contribution à l'étude de l'infection à VIH en milieu hospitalier à Bamako. ThèseMéd. 1988.

[7] Diabaté M. Contribution à l'étude de la prévalence de la séroconversion anti-VIH chez les lépreuxlépromateux à Bamako. Ecole de Méd. et de Pharmacie, Bamako 1988.

[8] Sitbon O, Lascoux-Combe C, Delfraissy JF, Yeni PG, Raffi F, De Zutter D et al. Prevalence of HIV-related pulmonary arterial hypertension in the current antiretroviral therapy era. Am J RespirCrit Care Med, 2008. 177(1): p. 108-13.

[9] Speich R, Jenni R, Opravil M, Pfab M, Russi EW. Primary pulmonary hypertension in HIV infection. Chest, 1991. 100 (5): 1268-71.

[10] Zuber JP, Calmy A, Evison JM, Hasse B, SchifferV, Wagels $\mathrm{T}$ et al. Pulmonary arterial hypertension related to HIV infection: improved hemodynamics and survival associated with antiretroviral therapy. Clin Infect Dis, 2004; 38 (8):1178-1185.

Citation: AbdoulayeKissima Traore, ZoumanaSangare, Modibo Doumbia, Charles DARA, Boubacar Diallo, AdamaSawadogo, Elie Dioma, Madou Traore, Ahmadou I Drame, Safi Bazi. Co-Mordibity Pulmonary Arterial Hypertension/HIV in the Provinces' Cardiology. ARC Journal of Cardiology. 2018; 4(1) 3-5 doi: dx.doi.org/11.20431/2455-5991.0401002.

Copyright: () 2018Authors. This is an open-access article distributed under the terms of the Creative Commons Attribution License, which permits unrestricted use, distribution, and reproduction in any medium, provided the original author and source are credited. 